\title{
CROSSING THE THRESHOLD: ENHANCING OPPORTUNITIES FOR PRACTICAL ENQUIRY IN SCHOOL SCIENCE THROUGH THRESHOLD CONCEPTS
}

\author{
Mark Deacon*
}

\section{ABSTRACT}

The higher education sector has been working with threshold concepts since they were first postulated in 2003. Threshold concepts offer a way to focus on areas of content which students find challenging to master. Once mastered, threshold concepts explain and integrate further areas of learning. In this sense threshold concepts can be regarded as liminal.

Although well established in the higher education sector, the use of threshold concepts has not been extensively explored in schools. This article focuses on Science in the upper secondary school. Yet it is possible to imagine scenarios where highly targeted teaching of liminal content leads to space being created for practical enquiry.

There is an established theoretical pedagogical framework within which threshold concepts can sit comfortably and will be familiar to school teachers. This framework also provides a route by which troublesome liminal knowledge can be taught.

There is then the question of defining and identifying threshold concepts. Threshold concepts do suffer from a lack of definition. Much of the literature explores ideas as diverse as complex physics and attitudes and values of nursery workers. This diversity has led to a discipline specific approach to defining concepts. It is argued that teachers can work with a range of stakeholders to identify troublesome knowledge.

This could alter curriculum planning, particularly time allocation, to specific troublesome content and provide time for a more diverse learning experience for pupils.

\footnotetext{
* Mark Deacon BEd. (Hons), PG.Dip., MSc, NPQH, FHEA.
} 


\section{INTRODUCTION}

The review 2014 of the National Curriculum brought in a different type of rigour to what pupils had to learn. The key curriculum change was a greater emphasis on the acquisition of factual knowledge. The second key change was to focus assessment on testing knowledge and that was to be rigorous. Thirdly, new public accountability structures introduced the EBacc and Progress 8 measures. The net effect has been to focus teaching into a narrower range of subjects and focus lesson time onto teaching the factual content.

It is argued that the drive to deliver what is perceived as a more rigorous academic curriculum has displaced arts subjects. There is also emerging evidence that opportunities for practical work in school science are declining, as teachers aim to cover the extended knowledge requirements of the GCSE syllabuses. Science departments are the focus of this paper.

Curriculum time is at a premium. There is competition for time, and some subjects are being squeezed. Within science there is an increase in demand, which has led to a decline in time-costly practical work. This is lamented, and alternative strategies need to be sought. Threshold concept theory provides a route for analysing the curriculum. Building a science curriculum using threshold concepts seems to offer a way forward. Using threshold concepts offer a way to plan highly targeted teaching with impact across several areas of the science syllabus. This could enable departments to free up time which could be used to enable pupils to engage in scientific enquiry.

Threshold concepts form part of the vocabulary of lecturers in higher education. However, the application of the ideas contained within threshold concepts is an under-researched area for schools. Search terms were applied in EBSCO: 'Threshold concepts in schools' returned four articles; 'Threshold concepts in school science' returned zero; as did 'Threshold concepts in GCSE science'.

\section{CURRICULUM CHANGE - ITS IMPERATIVES AND EFFECTS}

The National Curriculum in England has been in a state of evolution since it was introduced in 1988. As national concerns and priorities have changed, the curriculum has been adjusted to match those priorities.

On taking power in 2010, the Conservative Education Secretary Michael Gove called for a radical revision of the National Curriculum. Gove had a particularly conservative view of education and favoured a return to what he saw as traditional educational values. This was particularly reflected in debates around the history curriculum, where there was a shift in emphasis from understanding the process 
of historical enquiry to learning the key events of history and their impact (Mansell 2013) ${ }^{1}$.

There's been passionate - and welcome - debate about what should be in - or out - of the national curriculum. There are criticisms flying about the absence of Voltaire or a failure to give due prominence to the Manchu acquisition of the Mandate of Heaven. These complaints sit alongside, or come from the same quarters, as criticisms about the inclusion of the Anglo-Saxons or Oliver Cromwell. But in this debate, there is precious little attention given to what has actually gone wrong in too many of our classrooms.

The draft history curriculum is a direct attempt to address the failure over generations - to ensure children grow up knowing the story of our islands. It is inspired by existing good practice in the best schools - state and independent.

Gove, M. $2013^{2}$.

There were essentially two key drivers acting on Gove:

- The apparent declining position of the UK in the international comparison of educational outcomes the PISA Tests.

- Public concern over social unrest.

\section{THE PROGRAMME FOR INTERNATIONAL ASSESSMENT}

There is considerable debate around how much governments should allow a PISA position to influence their educational planning. As countries drop in and out of the PISA programme, league table positions shift. The PISA tests do not necessarily reflect what is taught in schools and have a unique way of posing questions (Kanes, C. Morgan, C. Tsatsaroni, A. 2014). ${ }^{3}$

Whilst PISA may mean very little to children and schools, it is regarded as a key indicator of a country's economic potential in comparison to other countries.

\footnotetext{
${ }^{1}$ Mansell, W. (2013) Michael Gove redrafts history curriculum after outcry. Guardian $21^{\text {st }}$ June 2013.

${ }^{2}$ Michael Gove Brighton College speech 9 ${ }^{\text {th }}$ May 2013 https://www.politics.co.uk/ comment-analysis/2013/05/09/michael-gove-s-anti-mr-men-speech-in-full (Accessed 01.04.20).

${ }^{3}$ Kanes, C. Morgan, C. Tsatsaroni, A. The PISA mathematics regime: knowledge structures and practices of the self Educational Studies in Mathematics 87(2) October 2014.
} 
Naturally this guides and informs investment decisions and is regarded as having a bearing on the economic health. (Gustafsson, J. 2018) ${ }^{4}$

The apparent decline relative to other nations in Britain's educational standards was blamed on schools' low expectations, poor behaviour and an unchallenging curriculum. There was also perceived grade inflation. This was summed up by Dominic Cummings, who at the time served as an advisor to Michael Gove:

There is widespread dishonesty about standards in English schools, low aspiration even for the brightest children, and a common view that only a small fraction of the population, a subset of the most able, should be given a reasonably advanced mathematical and scientific education, while many other able pupils leave school with little more than basic numeracy and some scattered, soon-forgotten facts. A reasonable overall conclusion from international comparisons, many studies, and how universities have behaved, is that overall standards have roughly stagnated over the past thirty years (at best), there are fewer awful schools, the sharp rises in GCSE results reflect easier exams rather than real educational improvements, and the skills expected of the top 20 percent of the ability range studying core A Level subjects significantly declined (while private schools continued to teach beyond A Levels), hence private schools have continued to dominate Oxbridge entry while even the best universities have had to change degree courses substantially.

Cummings, D. $2013^{5}$

The second driver was a perception that education was failing to deliver social stability. The social instability which marked the end of the Blair/Brown years was to be avoided in future. A narrative was developing around the inability or schools to instil a sense of community and social cohesion (Ball, S. 2017). ${ }^{6}$

This brings education firmly into the fore in the political arena, and Gove was determined to tackle this. There was also cynical or perhaps unfair view that Gove was driving an agenda based on his own school days based at Fettes College, Glasgow.

\footnotetext{
4 Gustafsson, J. (2018) International Large Scale Assessments: Current Status and Ways Forward 2018 University of Gothenburg, Gothenburg, Sweden Jan-Eric.Gustafsson@ ped. gu.se Accessed 02/04/20.

5 Cummings, D. 2013 Thoughts on Education and Political priorities. Available at https:// www.theguardian.com/politics/interactive/2013/oct/11/dominic-cummings-michaelgove-thoughts-education-pdf Accessed 04/04/20.

${ }^{6}$ Ball, S. (2017) The Education Debate (Third ed.) Policy Press. Bristol.
} 
Key influencers on policy makers included ED Hirsch (2006), ${ }^{7}$ whose views on a core-knowledge rich curriculum have proved to be extremely influential. Ironically for someone influential on the political right, Hirsch describes himself a left-leaning educationalist (Politico 2014). ${ }^{8}$ Hirsch regards a content-rich curriculum as essential for making up what he sees as a cultural deficit which is a limiting factor on the life chances of young people from poor backgrounds.

Another key influencer which links to the perceived declined in PISA scores was the approaches to teaching and learning which are used in high-performing economies such as Singapore and China (Worral 2015). ${ }^{9}$

There were also appeals to comparative recent developments in cognitive neuroscience which suggest that knowledge is built on knowledge. Where there is a knowledge deficit there needs to be direct teaching of core principles, which will then enable children to make progress (Rosenshine 2012). ${ }^{10}$

The force of all of these influences helped to produce the current knowledgedriven curriculum.

\section{SOME RESPONSES TO A KNOWLEDGE-RICH CURRICULUM}

A knowledge-rich curriculum required a knowledge-focused assessment system. Gove's reforms brought in revised assessment schemes, which were presented as more rigorous and knowledge-focused. The GCSE reforms resulted in examinations which had a bigger focus on recall.

The UK has had for some time a considerable focus on public accountability methods in the form of school league tables (www.gov.uk/government/ collections/statistics-performance-tables). An unintended consequence of the Progress 8 measure and the EBacc Imprimatur, curriculum choice has become restricted, as schools focus on the public accountability built into the education system.

There is a competition for curriculum time in schools. Schools have sought alternative ways to maximise the time available to deliver a programme of GCSE study which has the traditional breadth and allows for teaching of content and the development of skills.

\footnotetext{
7 Hirsch, ED. (2006) Why knowledge matters Houghton Mifflin. New York.

8 Politico.com 2014 ED Hirst - Biography. https://www.politico.com/ (accessed 3/4/20).

9 Worral (2015) Singaporean teaching methods improve UK maths skills www.ft.com/ content/11ed77a2-14eb-11e5-9509-00144feabdc0 Accessed 02/04/20.

${ }_{10}$ Rosenshine, B. (2012). Principles of Instruction Research-Based Strategies That All Teachers Should Know. American Educator. Volume 36. no.1 Spring 2012
} 
The approach of schools is summed up in the 2018 GL Assessment report $(6 / 12 / 18)$ which has been to:

- restrict the range of curricular provision available to pupils,

- restrict the Key Stage 3 experience by beginning the GCSE programme in year 9 ,

- $\quad$ early entry in some GCSE subjects such as RE and English Literature.

These strategies have raised concern with Ofsted. The chief inspector has made it a priority to ensure that children are still getting a broad and balanced curriculum. Additionally, the chief inspector wants to ensure that a pupil's Key Stage 3 experience is a whole experience and appropriate for KS3. In a sense this is about protecting pupil's experiences of the arts subjects. The curriculum has become a key focus for Ofsted, which will be conducting 'deep dives' to investigate the coherence of the provision (Ofsted 2019).

The consequence of the curricular changes has been a decline in the amount of time spent in practical science. Science departments have felt the competition for curricular time along with other subjects, particularly where heads have tried to protect the arts. The increased demands of the syllabus knowledge load are potentially significant. An unpublished curriculum audit conducted by the University of Brighton suggests that the number of key ideas and concepts which pupils need to master for the revised GCSE has risen by one third, plus mathematical processes and ideas. It is suggested that teachers carry out an informal cost-benefit analysis and practical work has been reduced. It does need to be acknowledged that the current GCSE syllabus requires that practical work is undertaken.

'Working scientifically' will be developed further at key stages 3 and 4, once pupils have built up sufficient understanding of science to engage meaningfully in more sophisticated discussion of experimental design and control.

DFE National Curriculum Science $2018^{11}$

The required practical work is a collection of standard school practical exercises which are going to be referred to in examination papers, but forms no part of examination practice (AQA 2018). It is suggested that teachers carry out an

11 DFE National Curriculum Science https://www.gov.uk/government/publications/ national-curriculum-in-england-science-programmes-of-study/national-curriculum-inengland-science-programmes-of-study Accessed 04/04/20 
informal cost-benefit analysis and practical work has been reduced to create space of the teaching of content.

This reflects a degree of cynicism around the benefits of practical work beyond the generic 'pupils enjoy it' (Abrahams 2009). ${ }^{12}$

This attitude has accelerated steady decline in the amount of practical work being done in science. There were already a number of reasons recognised for a reduction in the time spent in practical work The Science Community Representing Education report (2008) noted:

- Health and safety concerns,

- Teachers,

- Lack of experience,

- Cost,

And yet practical enquiry is seen as being at the heart of a good science education. The question is how can space for practical enquiry be created in science whilst working within the time constraints generated by curriculum pressures.

Current good practice suggests that teaching should be highly targeted. Which raises the question of which parts of a packed syllabus should be the focus of learning? One route to answering this question could be through analysing the curriculum through the lens of threshold concepts.

\section{THRESHOLD CONCEPTS AS A POTENTIAL WAY FORWARD}

Threshold concepts are liminal concepts which once mastered offer routes to understanding other ideas. They are also integrative in that a threshold concept is an idea which pulls other ideas together. This presents the potentially attractive idea that teaching focused on threshold concepts could reduce the time needed to be spend on other areas of the syllabus. Threshold concepts offer a way to streamline what is being taught. They are the means by which crucial points in a student's learning can be defined and mapped (Cousin 2006). ${ }^{13}$ The integrative function of threshold concepts will enable insights which can fill gaps in content learning. Framing how content is selected, presented and

\footnotetext{
12 Abrahams, I. (2009) Does Practical Work Really Motivate? A study of the affective value of practical work in secondary school science International Journal of Science Education Volume 31, 2009-Issue 17.

13 Cousin, G. (2019) Introduction to threshold concepts. Planet No. 17 December.
} 
assessed (Entwistle 2003; Land et al. 2006). ${ }^{14}$ Glynis Cousin (2006) offers an attractive point of view:

[a] focus on threshold concepts enables teachers to make refined decisions about what is fundamental to a grasp of the subject they are teaching. It is a 'less is more' approach to curriculum design.

\section{DEFINING THRESHOLD CONCEPTS}

Threshold concepts were proposed by Meyer and Land in $2003^{15}$ as a means of helping economics tutors in higher education support the learning of their undergraduates. They set up criteria to help identify those areas which are likely to cause students difficulty.

- Transformative: once understood, threshold concept changes the way the student views the discipline.

- Troublesome: the knowledge is counterintuitive, alien or incoherent.

- Irreversible: as they transformative they cannot easily be unlearned.

- Integrative: once learned they draw together different aspect of the discipline.

- Bounded: delimitates a particular conceptual space, serving a limited purpose.

- Discursive: extends the use of language.

- Reconstitutive: over time there will be a change apparent in the learner.

- Liminality: cross the thresh hold is akin to a rite of passage, a liminal space has been transversed.

Threshold concepts: A Short Introduction and a Bibliography from 2003 to 2018. UCL London https://www.ee.ucl.ac.uk/ mflanaga/thresholds.html Accessed 04/04/20

When dealing with threshold concepts it is important to consider their nature as liminal concepts. Liminality can be regarded as the process of opening a door. Once the doorway is traversed the student can enter a new realm of learning. That is regarded as progression into a new way understanding (Meyer and Land 2003). ${ }^{16}$

14 Entwistle, N. (2003). Concepts and conceptual frameworks underpinning the ETL project, occasional report 3. Enhancing Teaching-Learning Environments in Undergraduate Courses Project. Available at: http://www.tla.ed.ac.uk/etl/docs/ETLreport3.pdf.

15 Meyer, J. H. F., \& Land, R. (2005). Threshold concepts and troublesome knowledge (2): Epistemological considerations and a conceptual framework for teaching and learning. Higher Education, 49, 373-388.

16 Meyer, E. \& Land, R. (2003) Threshold Concepts and Troublesome Knowledge: Linkages to Ways of Thinking and Practising within the Disciplines Occasional Report 4. 
Conducting the student's journey is of great importance, and within the literature there are several examples of practice. Irvine, N. and Carmichael, P. $(2009)^{17}$ suggest that there is a process which goes through the stages of: mimicry of established scholars, internalisation and active shaping of outlook.

Others see liminal progression as a spectrum through which students' progress gradually; introduction of concept, internalisation to definition and engage with application (Kabo and Baille, 2010). ${ }^{18}$ This of course has implication for teaching, as students are unlikely to progress at the same rate along the spectrum. Indeed, some become stuck at a particular point and are unable to progress.

There is a body of evidence around discipline-specific shared ways of thinking. As Meyer 2016 observes: disciplines have their own specific content knowledge, ways of thinking about it and behavioural norms. Solomon (2006) ${ }^{19}$ stressed that there is a need to engage in argument and interpretation to understand how a discipline develops shared ways of thinking. Solomon cites mathematical proofs as an example where students see a proof as something to be mastered and not as an intrinsic part of thinking like a mathematician.

This is typified by a study of trainee doctors (Randall, Brooks, Montgomery, McNally, 2018). ${ }^{20}$ Trainee doctors were asked a series of questions aimed at identifying when they began to 'think like a doctor'. This of course illustrates that liminality goes beyond a body of knowledge and ideas and extends to through processes and key behaviours. Interestingly this study was repeated in different countries and a remarkably consistent set of results were produced.

Once the liminal step has been taken, students can then more easily move on to other ideas in the same discipline. Threshold concepts can therefore be considered to be discipline-specific. However, it will be differences between individuals as they progress towards mastery. The concepts do provide a foundation for further learning in the discipline. Students demonstrate content knowledge through discursive symbols, such as representative language or behaviour, as well as the ability to correctly decipher disciplinary language (Meyer and Land, 2005).

17 Irvine, N., and Carmichael, P. (2009). Threshold concepts: A point of focus for practitioner

18 Jens Kabo and Caroline Baillie (2010) T Negotiating the Spectrum of Liminality in Threshold Concepts and Transformational Learning. Vol 42. pages 303-315 Sense Publications Rotterdam isbm 9789460912601

19 https://www.mededpublish.org/manuscripts/1866 accessed 27/04/20

20 Virginia Randall, Robert Brooks, Agnes Montgomery, Lauren McNally (2018) Threshold Concepts in Medical Education. MedEd Publishing 
When the threshold has been passed there is a sense of joining a community of discipline. Meyer and Land (2005) noted:

When employed by experts, discipline-specific language and behaviour represent more than specialized discourse. Such efforts reveal how scholars see themselves, in addition to the manner through which they construct knowledge, view the discipline, shape disciplinary identity, and foster a sense of belonging to the body of scholars in that area

\section{DEFINING AND FINDING THRESHOLD CONCEPTS}

Defining threshold concepts has become a problem, as different disciplines in the higher education sector have used the idea to support their students learning. There are significant numbers of studies where disciplines have used the idea of threshold concepts to identify areas which their students find difficult to master.

Examples of discipline specific knowledge:

- Physics - gravity

- Economics - opportunity cost

- Biology - cells

- Medicine - pain

Examples of discipline-specific behaviours:

- Medical reasoning - thinking like a doctor

- Pharmaceutical practice - managing patients

- Approaches to early years children

The striking feature of the vast amount of subject-specific studies is the eclectic mix of subjects which are being identified as threshold concept. The range of thresholds seem to cover skills, key areas of knowledge, art techniques and interpersonal skills. Of course, all of these are valuable and need to be mastered to gain the desired professional status.

This has led to a consideration of the nature of what different practitioners and researchers are labelling as concepts. Concept is a philosophical term for the building blocks of thought. In education concepts can be thought of as mental representations, abilities or abstractions. Most educators will understand that these have been extensively explored by Piaget, Vygotsky 
et $a{ }^{21}{ }^{21}$ this gives us an immediate problem when discussing threshold concepts in that the diversity of application of the theory has left us with a difficulty in that many of the applications of threshold theory do not easily fit into any of the categories of the scholarly view of concepts (Stanford Encyclopedia of Philosophy). ${ }^{22}$

Because of the transferability of the definition of threshold concepts it is argued that it is better to let disciplines decide what is the most appropriate definition of a threshold concept. Meyer notes that across disciplines there is a remarkable similarity between aspects of each discipline that are identified as threshold concepts. Meyer goes on to propose a strategy of allowing teachers to decide what constitutes an area of difficulty for students and are 'recognised as barriers to learning'. This then raises the question as to whether or not it is helpful to think of these elements of the curriculum not as threshold concepts but as 'threshold content'.

Some everyday concepts such as 'burnout' in the healthcare and other occupational professions are a product of social construction that linguistically embrace a range of commonly experienced or observed human conditions, while others such as the aforementioned 'limit' are precise mathematical abstractions. And, in-between there is much room for the positioning of consensus in the first stages of identifying threshold concepts.

(Meyer 2016)

There then remains a question as to how we should be defining threshold concepts and how can that process of identification work. Barradell $(2013)^{23}$ suggests there are three perspectives which need to be brought to bear:

1. that the identification process needs to have rigour;

2. that transactional curriculum inquiry amongst academics, students and educational developers is important; and

21 Stevens-Fulbrook, P. (2020) Vygotsky, Piaget and Bloom.: The Definitive Guide to their Educational Theories with Examples of How they can be Applied. (Learning Theories Book 2) Kindle Edition

22 Plato.standford.edu (accessed 3/4/20)

23 Barradell, S. Kennedy-Jones, M. (2015) Threshold concepts, student learning and curriculum: making connections between theory and practice. Australia Innovations in Education and Teaching International, 2015 Vol. 52, No. 5, 536-545 research. Active Learning in Higher Education, 10(2), 103-119.

Barradell, S. (2013) The identification of threshold concepts: a review of theoretical complexities and methodological challenges. High Educ (2013) 65:265-276 DOI 10.1007/ s10734-012-9542-3 
3. that this process might be strengthened if it involved participants beyond the educational domain.

Barradell goes on to suggest that consensus between these three strands is going to be important.

The literature contains a range of methodologies used within a range of higher education settings. The first key question is that of sample selection. Barradell (2013) notes that in much of the research sample sections are limited to those in the immediate educational domain rather than the wide communities of practice in the associated professions. Walker $(2012)^{24}$ includes an impassioned plea that the learners should be the focus of the enquiry into the nature of threshold concepts. He notes that 'what we think of them (threshold concepts), might not be what they think of them'.

Much of the research around engaging students in the identification of threshold concepts has involved small populations. Typically, Mangan, J. and Davies, P. (2015), ${ }^{25}$ writing about economics undergraduates the sample selection was confined to first year students and their lecturers. However, Barradell's point would suggest that there should be a wider consultation with those who are practising economists bringing in a wider sample with a depth of knowledge born out of practice.

There is a range of methodologies represented in the literature; these include:

- reflective journals,

- questionnaires,

- focus groups,

- measuring student response against expert views,

- iterative analysis or interviews,

- $\quad$ scrutiny of past examination papers.

Timmermann and Meyer (2017) ${ }^{26}$ offer a useful framework for thinking through how we might find threshold concepts. Their framework offers clusters of actions which educators can take to help identify threshold concepts.

${ }^{24}$ Walker, G. (2013) A cognitive approach to threshold concepts. High Educ (2013) 65:247-263 DOI 10.1007/s10734-012-9541-4.

25 Mangan, J. Davies, P. Recognising Threshold Concepts: an exploration of different approaches. Paper presented at the European Association in Learning and Instruction Conference (EARLI) August 23 - 37th 2005, Nicosia, Cyprus

${ }^{26}$ Meyer, J. \& Timmermans, J. (2017) A framework for working with university teachers to create and embed 'Integrated Threshold Concept Knowledge' (ITCK) in their practice Pages 354-368 Published online: 17 Oct 2017. 
Cluster 1 is essentially talking to people. For teachers this ought to be stating the obvious. We need to talk to colleagues, experts and, most importantly, our pupils. What is knowledge and first- and second-person experience telling us is getting in the way of progress? This resonates with some of the current work being done in medical schools, where there is remarkable consistency between trainee doctors in medical schools around the world as to what they need to master before being able to think in a clinical way.

What is an expert understanding of a subject area? This is Cluster 2 thinking. How do experts in the subject and teachers (who of course may not be experts) in a specialised area of knowledge conceptualise the area? This process needs to finish with naming the threshold concept in one or two words, an important step as it enables the teacher to crystallise the idea, grasping its essence.

Clusters 3-7 are concerned with designing effective teaching scheme with appropriate learning objectives, activities and assessments which will guide learners through the process of cross the threshold concept.

Timmermann and Meyer's approach is summarised diagrammatically as

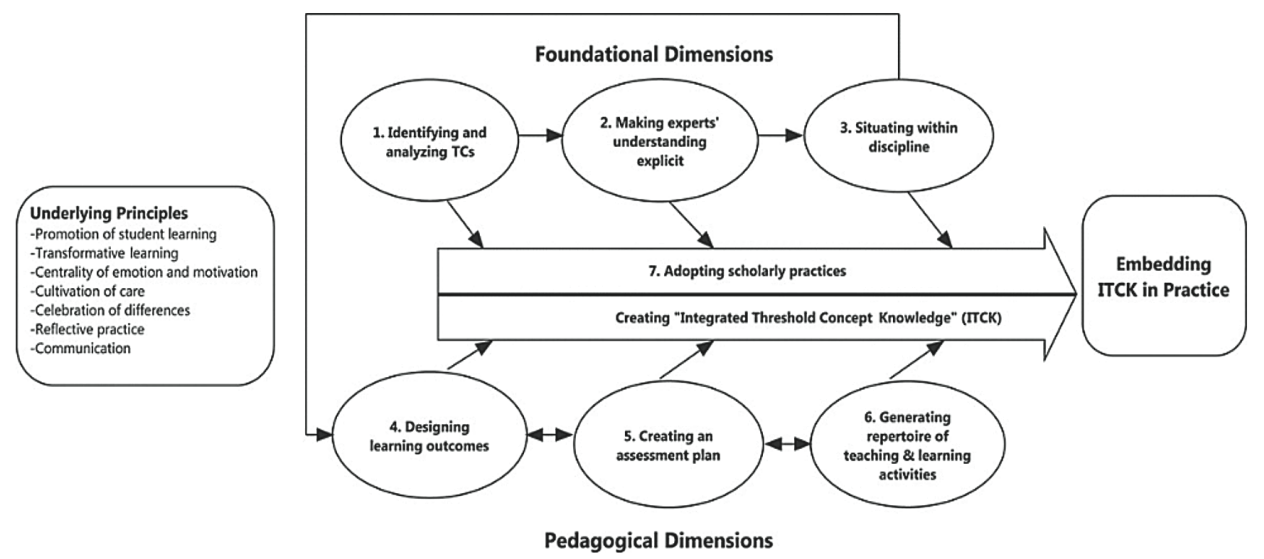

A defining feature of much of the work in higher education is collaboration between institutions, which enables a degree of comparison and allows for some variation in the learning experience. Where researchers have worked collaboratively there is a striking similarity in their findings. This even seems to work on an international basis. A study of medical students in America and England showed remarkably similar results (Virginia Randall, Robert Brooks, Agnes Montgomery, Lauren McNally 2018). ${ }^{27}$

${ }^{27}$ Randall, V., Brooks, R., Montgomery, A. \& McNally. L. ( 2018) Threshold Concepts in Medical Education. Dundee: MedEdPublish 
Like the discussion on the use of the term 'concept', there would appear to be an emerging pragmatism over the features of threshold concepts. Baradell (2015) notes:

Threshold concepts may never be a 'one size fits all'; disciplinary differences regarding ways of thinking and practising professionally, academically and pedagogically make sameness impossible and probably unnecessary.

There is a discussion to be had concerning how many features of a threshold concept a problematic area of a discipline needs to have to be considered a threshold. Meyer and Land (2005) noted that this is still an emerging field. There is still a discussion to be had concerning how many of the five characteristics does a 'concept' need to have to be considered a threshold concept. Barradell (2013) asks, if something is troublesome and integrative but not transformative, is it still a threshold concept? It has been argued (Davies and Mangan 2005) ${ }^{28}$ that 'transformative', 'irreversible' and 'integrative' are interwoven, and that 'bounded' and 'troublesome' derive from those - the implication being that a threshold concept should possess all five. In practice this is rarely observed. Studies across disciplines have shown that "troublesome" and "transformative" areas of content are significantly overrepresented in definitions of threshold concepts. However, Meyer (2016) ${ }^{29}$ writing alone notes that in earlier work Meyer and Land use words like 'probably', 'possibly' and 'potentially' as qualifiers for all the features of a threshold concept. Meyer stresses that this apparently loose language is important and should not be ignored, otherwise unsupportable claims are made which seem to ignore differences between individuals' progression through a discipline.

\section{TESTING A POTENTIAL THRESHOLD CONCEPT}

A good test of a putative threshold concept is that it should function horizontally and vertically; i.e. it should allow for progression (liminality) and draw together concepts from other disciplines (integrative) (Barradell 2013).

28 Davies, Peter \& Mangan, Jean. (2005). Recognising Threshold Concepts: an exploration of different approaches. Paper presented at Eurpoean Association in Learning and Instruction Conference August 23-27 2005 Nicosia Cyprus researchgate.org accessed 27/04/20 https://www.researchgate.net/publication/228377119_Recognising_Threshold_ Concepts_an_exploration_of_different_approaches

${ }^{29}$ Meyer, J. (2016) Threshold concepts and pedagogic representation Education + Training Vol. 58 No. 5, 2016 pp. 463-475 @EmeraldGroupPublishingLimited 0040-0912 DOI 10.1108/ET-04-2016-00. 
An example of this is surface-area-to-volume ratio (SA:V), which is extensively represented in current GCSE science syllabuses. It is an idea pupil find difficult to understand, explain and calculate. The reasons for this are:

- difficulty in understanding variables,

- teachers have learned the process by rote and do not necessarily understand it,

- difficulty understanding that the variables function independently of each other, and

- difficulty with the mathematical concept of ratio.

(Cohen, More and Chayoth 1999) $)^{30}$

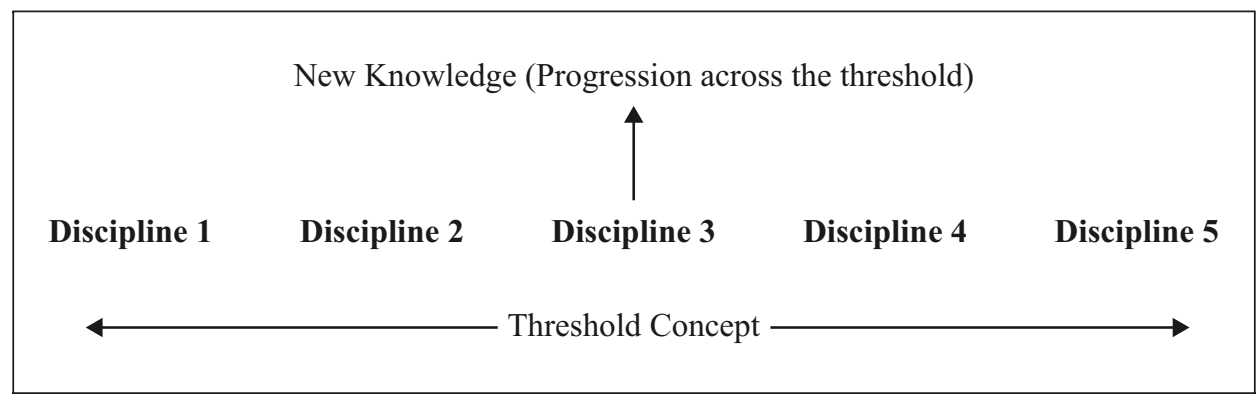

Fig. 1 Schematic of Horizontal and Vertical Function of Proposed Threshold Concept.

\section{SETTING SA:V AGAINST MEYER AND LANDS CRITERIA}

- Transformative: mastery of SA:V will enable pupils to offer explanations of familiar yet complex phenomena.

- Troublesome: when pupils start to calculate SA:V they quickly become confused as small organisms become big organisms this is counterintuitive.

- Irreversible: not immediately clear if this condition applies*

- Integrative: there are many situations in science where the size of an organism or particle affects the way it performs or reacts.

- Bounded: it is a single idea which has many applications

- Discursive: pupils struggle with language in science, and in this content big becomes small, which means they have to use language in a more complex way.

${ }^{30}$ Cohen, A., Moreh, B. \& Chatoth, R. (1999) Hands-On Method for Teaching the Concept of the Ratio between Surface Area \& Volume The American Biology Teacher Vol. 61, No. 9 (Nov. - Dec., 1999), pp. 691-695. 
- Reconstitutive: not immediately clear if this condition applies*

- Liminality: This is a concept which recurs at many levels. Pupils need to master it to make progress.

* At the outset it is hard to say if the idea of SA:V is irreversible or reconstructive. However, as noted above, to be considered a threshold concept it is unlikely that any one item of content will need to fulfil all the criteria.

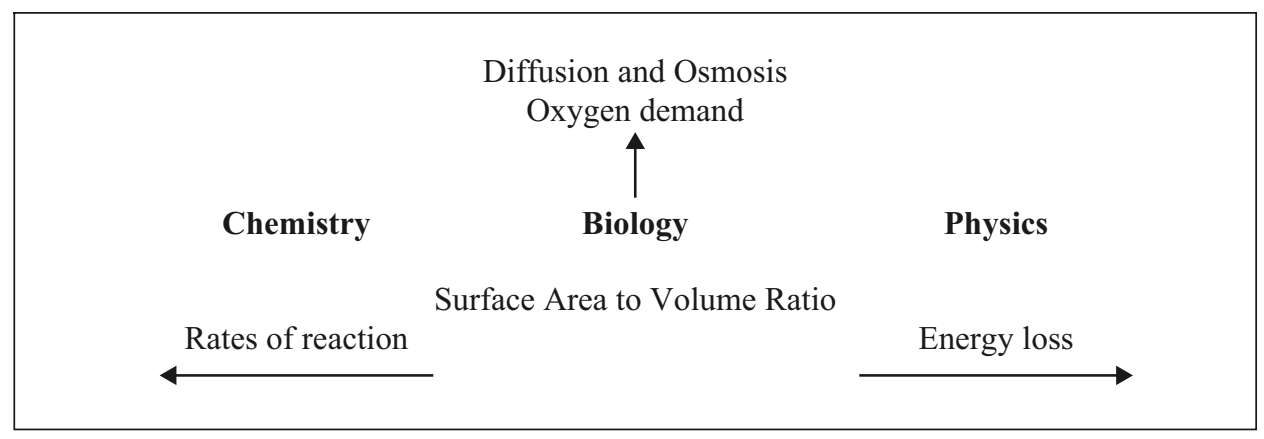

Fig 2. Consideration of Surface-Area-to-Volume Ratio as a Threshold Concept as Vertical and Horizontal Content.

\section{IMPLICATIONS FOR PEDAGOGY}

\section{Location within the landscape of education theory}

Whilst threshold concepts are making tentative progress into the vocabulary of schoolteachers, it is still largely unfamiliar territory in schools. Discussions in research has largely been centred on undergraduates and those entering specialist postgraduate training, e.g. Neurology (Moellera and Fawn 2018). ${ }^{31}$

Schoolteachers will need to be able to locate threshold concepts within the theoretical frameworks they understand. Walker (2013) sought to locate threshold concepts within cognitive theory and draws some very helpful parallels with longestablished schema theory.

31 Moellera, J. \& Fawns, T. (2018) Insights into teaching a complex skill: Threshold concepts and troublesome knowledge in electroencephalography (EEG) MEDICAL TEACHER, 2018 VOL. 40, NO. 4, 387-394. 
Schema theory is familiar territory for teachers, having been foundation in teacher training programmes for many years. It was proposed by Bartlett $(1932)^{32}$ as a model for how experiences shape behaviours. Scheme can be considered templates against which we measure the world. A scheme is an elaborate thing which is flexible and is essentially reactive, depending on what we are experiencing (Reber 1995). ${ }^{33}$

In education and throughout teacher training, schema theory has been taught through the work of Piaget. (Fulbrook-Stevens 2020). This brings teachers into familiar territory. Walker sets out Anderson's criteria for schema, which immediately draw some obvious parallels with the defined features of threshold concepts:

1. Schema are transformative (they are reorganised when incoming data reveal a need to restructure the concept) and represent a personal ontology (they are organised in a way that is meaningful to the individual).

2. Schema tend to be irreversible (schema are malleable and changeable momentby-moment as information is received).

3. Schema are integrated (schema are embedded in other schemata, which themselves subsume sub-schema).

4. Schema are bounded (schemas enable gestalt or holistic representations which recognize the boundaries between concepts).

5. Schema can represent 'troublesome knowledge' (they often run counter to common sense and have a strong affective component).

Anderson (1977) in Walker (2018)

This helpful tabulation shows the significant amount of conceptual overlap between schema and threshold concepts. It is important to make the semantic step of recognising that not all threshold concepts are schema and not all schema are threshold concepts.

Using the schema approach, we can start to understand what may be 'troublesome knowledge' which becomes liminal and potential causing progression to stop. As pupils progress through the curriculum, they have to remake, create schemas and link schemas. This is a process which pupils find difficult, as it can introduce cognitive dissonance as well as be influenced by the environments.

\footnotetext{
32 Bartlett, F. C. (1932). Remembering: A study in experimental and social psychology. Cambridge: Cambridge University Press.

33 Reber, A. (1995). Implicit learning and tacit knowledge: An essay on the cognitive unconscious. New York: Oxford University Press. In Watson (2013).
} 
This brings teachers straight into familiar territory. Best practice suggests that teachers need to approach troublesome knowledge through general knowledge and generic concepts (prior learning). The next step is to help students to restructure their learning in ways that integrate it.

Cousin $(2006)^{34}$ suggests that curriculum design should be orientated towards understanding and developing practice which will enable pupils to master troublesome knowledge. She offers four principles which could lead to mastery of threshold concepts:

- Explore what appear to be threshold concepts,

- Listen to what pupils are saying, especially the language they are using to shape their knowledge,

- Tolerate confusion and take pupils through what is confusing them,

- Revisit learning.

\section{Exploration of apparent threshold concepts}

As set out above the process of identification of threshold concepts involves a dialogue of experts in the field. This is sharing of knowledge and experience which reaches a consensus as to what students find difficult. Other strategies employed in higher education include work and examination scrutiny. This can provide invaluable information about areas pupils are finding difficult to access and explain. One of the areas already explored is the engagement of practitioners outside the immediate context of the institution. Engaging with the wider community of practice must surely be a good thing for science teachers.

\section{Listen to pupils}

The power of student voice is already recognised. Within the research literature there is a considerable body of evidence for the effectiveness of this. A range of consultation methods have been used largely to good effect: surveys, semi-structured interviews and observations. Cousin does remind us to be careful listeners to the language pupils are using.

${ }^{34}$ Cousin, G. (2016), "Foreword", in Land, R., Meyer, J. H. F. and Flanagan, M. T. (Eds), Threshold Concepts in Practice, Sense Publishers, Rotterdam, pp. ix-x. 2006. 


\section{Tolerate confusion}

There needs to be space created for pupils to articulate their confusion with supportive teachers; this of course touches on areas of classroom management and planning which probably do not arise in HEIs: behaviour management, extension and support tasks, etc.

\section{Revisit learning}

With the growth of understanding of memory and practice development through cognitive neuroscience, revisiting prior learning is becoming established good practice and is already incorporated into lesson planning.

At the department level identification of threshold concepts could guide the planning of schemes of work. The liminal nature of threshold concepts makes them worthy of sufficient time which if effective can make progression faster. The integrative nature of threshold concepts should have transdisciplinary impacts, particularly in closely related disciplines.

\section{CONCLUSION}

In this paper I have sought to show that we have a knowledge-rich curriculum which is altering the way teachers are delivering lesson. The focus has been science, where it is suggested that this is reflected in a further pressure to reduce practice enquiry.

Threshold concepts seem to offer a route to make teaching and learning more effective. Threshold concepts are at their heart liminal and enable pupils to move forward rapidly once mastered. A problem within the research is that the definition of threshold concepts is deliberately vague. This has resulted in an evolution in practice, where each discipline has sought to make threshold concepts their own. This has made the term 'concepts' unhelpful; perhaps the term threshold content is more helpful. However, we are left with a means to analyse curriculum in order to identify troublesome knowledge, which is in and of itself helpful. Most authors agree that to identify threshold concepts requires input from experts, students and the wider community of practice.

There are areas of challenge and complexity which seem to offer themselves as potential threshold concepts.

It is suggested that to use the ideas of threshold concepts in schools we need to situation the practice within established learning theory. There is limited research in this area, but situating threshold concepts within schema theory has the 
CROSSING THE THRESHOLD: ENHANCING OPPORTUNITIES FOR PRACTICAL ENQUIRY IN SCHOOL SCIENCE THROUGH THRESHOLD CONCEPTS

potential to be a good fit. This also situates it into territory which is familiar to teachers.

Much of what is currently considered good practice - e.g. revisiting learning, presenting the meta picture at the start, building on existing knowledge - indicates how teachers can support pupils as they cross thresholds.

Threshold concept theory seems to offer a way forward in planning the way we direct the time allocations given in the current curriculum. This then offers the opportunity to open up time for aspects of the curriculum other than content acquisition for example - practical enquiry. 